\title{
Resex marinha versus polo naval na baía do Iguape
}

Cathérine Prost - Doutora pela Université de Paris VIII (1999). Professora adjunta da Universidade Federal da Bahia e do Programa de pós-graduação em Geografia da UFBA. E-mail: cathprost@yahoo.com

\section{Resumo}

A Reserva Extrativista (Resex) marinha Baía do Iguape, situada na Baía de Todos os Santos (BTS), exemplifica a política federal de conservação ambiental fundamentada no uso sustentável dos recursos naturais por populações tradicionais. Contudo, em 2009, o governo estadual propôs a instalação de um polo naval na extremidade sul da Resex. Dessa forma, a instância de decisão da unidade de conservação é desrespeitada por não ter sido consultada e as comunidades pesqueiras se veem diante da perspectiva de riscos no tocante à preservação do meio natural, base de seu sustento. O projeto governamental, que defende uma visão desenvolvimentista e anuncia uma elevada oferta de empregos, foi precedido de um breve estudo que não levou em conta os potenciais efeitos sociais de tal empreendimento. Configura-se, portanto, uma desterritorialização econômica, política e cultural - na imobilidade - das populações tradicionais, diante da imposição da lógica global no lugar. Este artigo analisa as relações de força entre os diversos agentes sociais, assim como os riscos que o empreendimento representa para as populações.

\begin{abstract}
The marine extrativist reserve (Resex, reserve of collect) Bay of Iguape, localized in the Bay of all Saints is un example of the federal policy of environmental protection, funded on durable use of natural resources by traditional populations. Composed of 20 communities practising fishing and/or agriculture, it has been created in 2000. Its deliberative counsel has been settled in 2005 for planning and management, in partnership with the Institute Chico Mendes and Biodiversity. However, in 2009, the State government of Bahia has proposed the installation of a naval pole on the extreme south of the Resex. In this way, the sphere of decision of the unit of conservation is disrespected as it hasn't been consulted and the fishering communities are face perspectives of risks relative to the preservation of the natural ambient, base of their economical survival. The governmental project, that defends a development vision and announces a high offer of jobs, has been preceded of a brief study that didn't consider the potential social effects of such an enterprise. It configures so an economical, political and cultural desterritorialization - in the immobility - of the traditional populations because of the imposition of global logic in the place. This paper intends, so, to analyse the relations of strength among the diverse social agents as the risks that the enterprise represents for the populations.
\end{abstract}

\section{Keywords}

Marine extrativist reserve. Participation. Economical development. Naval pole.
Reserva extrativista marinha. Participação. Desenvolvimento econômico. Polo naval. 


\section{INTRODUÇÃO}

A zona costeira, embora estreita, do ponto de vista de sua extensão no globo terrestre, aparece, todavia, como uma área específica, por ser interface entre continentes e mares e oceanos. O litoral sempre foi muito atrativo, pela presença de recursos pesqueiros, de ecossistemas particulares de alta riqueza ecológica (restingas, manguezais etc.), importantes em várias escalas, do local onde se situam até a vida marinha em geral, mas também como plataforma para a descoberta do mar e das terras além-mar. Observa-se, contudo, no século XX, uma tendência à "litoralização das formas de ocupação do espaço" (MIASSEC, 2001). Certos usos do solo ocorrem essencial ou principalmente na faixa costeira. Dentre as atividades registradas nessas áreas do planeta, citam-se a pesca, a navegação, a atividade portuária e o turismo litorâneo. Outros usos do solo não são atrelados a esse tipo de área, mas tendem a privilegiar sua implantação; é o caso de certas indústrias e - particularmente no caso brasileiro - da urbanização. Miassec (2001) salienta que a revolução industrial do século XIX não foi fundada sobre uma revolução das tecnologias marítimas, salvo o vapor. Já a partir dos anos 1950, desenvolve-se uma verdadeira revolução dos transportes marítimos, permitindo uma "maritimização do mundo". A diversidade dos usos do solo e dos recursos hídricos pode se traduzir por uma potencial conflituosidade entre eles.

O recorte espacial em escala local aqui utilizado para ilustrar esses conflitos é a baía do Iguape, pertencente à Baía de Todos os Santos, situada a cerca de $100 \mathrm{~km}$ a leste de Salvador. A baía do Iguape abrange uma reserva extrativista (Resex) marinha que se estende sobre águas interiores - cuja principal origem é o rio Paraguaçu - e manguezais. Criada em 2000, ela visa proteger principalmente os ecossistemas de manguezal e aquáticos, assim como o modo de vida das populações locais extrativistas - pescadores, incluindo marisqueiros - em uma lógica de conservação ambiental. Em 2005, o conselho deliberativo da Resex foi criado com a eleição dos diversos delegados, no intuito de conduzir o planejamento e a gestão da unidade de conservação (UC). Contudo, apesar da existência da UC, o governo estadual decidiu implantar um polo naval - projeto reduzido ao de ampliação de canteiro naval após consulta à população local - ao sul do território da Resex, sem os preliminares e necessários debates e tomada de decisão no seio da Resex.

Esse trabalho objetiva, portanto, apresentar à reserva extrativista Baía do Iguape, o modo específico de funcionamento desse tipo de unidade de conservação, assim como prever o caráter conflituoso com o projeto em curso, de ampliação de canteiro naval, cujos potenciais efeitos devem se traduzir em aspectos negativos sobre a dinâmica da área, do ponto de vista ambiental, social e econômico.

A metodologia utilizada, além de levantamento bibliográfico, de trabalhos de campo com aplicação de questionários e entrevistas para conhecer a área de estudo, assim como de participação em audiência pública e em reuniões da Comissão Pró-Iguape ${ }^{1}$, no intuito de consolidar as discussões acerca dos riscos potenciais e da mobilização das populações locais.

\section{A ZONA COSTEIRA, UM ESPAÇO GEOGRÁFICO RARO E ESTRATÉGICO}

A localização litorânea coloca como pressuposto usos particulares, sendo alguns deles praticamente exclusivos dessa área. Com a revolução industrial, as necessidades de matérias-primas como ferro e carvão aumentaram; para os países que não as possuíam, era necessário importá-las. Devido ao seu caráter ponderoso, o transporte marítimo apareceu como o mais adequado. A revolução desse meio de transporte, após a Segunda Guerra Mundial, permitiu um aumento exponencial, graças à especialização dos navios e à elevação das capacidades de carga (MESSIAC, 2001). Além disso, como observa Moraes (2007), as zonas costeiras constituem as bases terrestres de exploração dos recursos marítimos, tendo, em primeiro lugar, os recursos pesqueiros, mas também recursos minerais, como é o caso da camada pré-sal, descoberta ao largo da costa brasileira (frente aos estados de São Paulo, Rio de Janeiro e Espírito Santo). A diversidade desses recursos indica, desde já, o caráter estratégico do litoral para a exploração dos mesmos. Salienta-se que, o domínio de fachada litorânea permite, graças ao avanço das tecnologias, o domínio sobre espaços marítimos e seus recursos, interesse que ganha destaque nas últimas décadas e está cada vez mais regulado por normas e acordos internacionais. De modo a viabilizar a exploração desses recursos marítimos, acompanham infraestruturas especiais, como portos, indo de recortes da linha de costa, oferecendo abrigo natural, até os terminais portuários, com

A Comissão Pró-Iguape é formada por representantes de organizações sociais (Movimento da Pesca, Conselho Pastoral dos Pescadores, etc.), entidades que tratam de temas ambientalistas (Gérmen, Instituto Búzios, Onda Azul, Gambá) e instituições de ensino e pesquisa (MGEOUFBA). 
seus equipamentos de transbordo e de armazenamento de mercadorias diversas. Desempenham uma função importantíssima ainda hoje, visto que a maior parte do transporte intercontinental de mercadorias utiliza o meio marítimo como principal via de transporte. Embora se possa citar notáveis portos fluviais, graças à trafegabilidade de largos rios, como é o caso de Manaus, a cerca de $1.500 \mathrm{~km}$ no interior das terras amazônicas, os portos marítimos mantêm a esmagadora predominância nos fluxos de grande distância, que representam cerca de $80 \%$ do comércio mundial. Em uma configuração territorial como a brasileira, em que as ferrovias não chegaram a ser concebidas como uma rede de integração nacional, a localização costeira conserva um alto valor estratégico nos fluxos nacionais de circulação, além do forte peso dos internacionais.

Outro uso do solo, muito mais recente na história da humanidade, mas que ganhou uma importância significativa desde o século passado, reside no turismo, promovido pelas conquistas trabalhistas de férias pagas e pelo aumento do nível de vida nos países industrializados, a partir dos anos 1950. As praias se tornaram espaço de lazer e os sítios ambientalmente mais preservados, ensolarados e considerados de alta beleza cênica, que atraem o imaginário de massas de citadinos em busca de férias para descansar ou, eventualmente, praticar esportes aquáticos.

No tocante à distribuição geográfica da população mundial, embora essa seja dispersa no conjunto das terras emersas, observa-se, em várias escalas, uma predominância da ocupação humana em área costeira. Moraes (2007, p. 21) lembra que "cerca de dois terços da humanidade habitam em zonas costeiras, localizandose à beira-mar a maior parte das metrópoles contemporâneas". Portanto, a densidade no litoral se revela alta, embora desigual, ao longo das linhas da costa.

Uma consequência que deriva em parte dessa concentração populacional reside na implantação de muitas indústrias. A teoria de localização industrial leva em conta uma série de fatores ${ }^{2}$ para explicar a distribuição geográfica desse setor econômico. O Brasil figura como um exemplo por excelência de concentração de vários dos fatores citados na faixa litorânea, em decorrência do padrão de ocupação a partir da costa atlântica por parte dos colonizadores portugueses, e de uma "interiorização" mais efetiva do interior do país, apenas a partir da segunda metade do século XX. Atualmente, a concentração populacional na zona costeira,

2 Preço de compra do terreno e construção do estabelecimento, preço da energia, nível de impostos, proximidade da matéria-prima/recurso a ser processado ou água, proximidade dos eixos de comunicação, proximidade da mão de obra, proximidade de outras indústrias complementares, proximidade dos mercados consumidores incluindo a concentração de numerosas metrópoles, acarreta a concentração de mão de obra e de mercado consumidor, assim como a de indústrias nas regiões mais desenvolvidas economicamente. Com isso, conclui-se que o alto valor estratégico da fachada litorânea, especificamente no Brasil, onde os vetores de urbanização espontânea ou não - de industrialização e de turismo se mostram muito dinâmicos.

Mas, se o litoral apresenta vantagens locacionais ímpares, lembra-se que se trata de um espaço relativamente escasso, se comparado com a extensão das terras continentais. Esse caráter lhe atribui um potencial de geração de renda diferencial, podendo levar a uma renda monopolística, quando do controle de um local "de qualidade especial em relação a algum tipo de atividade" (HARVEY, 2005, p. 222), mas também - ou justamente por isso - a uma potencial conflituosidade entre usos. Diversas escalas e paradigmas de valores são confrontados nos debates contraditórios acerca dos usos do espaço costeiro.

Em um período marcado pela preocupação com um desenvolvimento com sustentabilidade ambiental, a economia ambiental tem desenvolvido instrumentos de valoração dos recursos naturais, conferindo valor aos serviços ambientais, ou ainda estimando os custos de impactos negativos sobre os ecossistemas. Todavia, como observa Moraes (2007), os recursos ambientais, "condições de vida e produção", são de contabilização muito mais complexa, ao envolver considerações mais subjetivas, como as belezas cênicas, por exemplo. O debate, embora avançado, não forma consenso. Uma possibilidade é a de buscar uma valoração de base espacial - o valor dos lugares, composto pelo conjunto dos recursos de um lugar, equação muito mais complexa, uma vez que a totalidade não se reduz à soma de seus componentes. O lugar é entendido então como "um espaço de produção e reprodução de um grupo humano, uma possibilidade de uso social com um dado potencial produtivo, o qual permite uma abordagem vocacional que desvendaria suas vantagens e desvantagens (em face de cada uso), em comparação a outros lugares" (MORAES, 2007, p. 19). Parafraseando Santos (2008), ele é o lócus que permite ao Mundo, entendido como modelo de produção global, realizar-se em função de seus atributos. O lugar é, portanto, determinado, não só pelos recursos que abarca, mas também pela sua localização e caracterização geral. Moraes propõe, então, a noção de valor contido, em que residem fatores naturais e históricos, com destaque para as técnicas. Mas, é necessário também levar em consideração o valor criado, pelo modo de exploração do lugar, determinado em função dos diversos interesses em jogo. $\mathrm{O}$ autor afirma que a sustentabilidade deve seguir 
a opção por usos que permitam a "manutenção das maiores possibilidades de exercício de outros usos” (MORAES, 2007, p. 20).

Mas, observa-se que se a valoração consiste em atribuir valor de troca a bens ou conjuntos de bens, a valorização remete à apropriação material, transformando recursos da natureza em valores de uso. A valoração é contabilizada por economistas, enquanto a valorização é o feito de classes sociais excluídas dos grandes circuitos da economia e, no nosso país, sistematicamente marginalizadas, em favor da lógica excludente capitalista. Estes usam, de fato, uma certa valoração dos recursos naturais (através da venda, por exemplo), mas a valorização dos lugares contempla também um conjunto de relações sociais historicamente construídas, o espaço banal enunciado por Santos (2002). Para as populações tradicionais, a natureza não representa apenas um amontoado de recursos, mas também um abrigo, por ser um local de moradia, um local onde se exercem relações de solidariedade orgânica e que contém valores simbólicos que contribuem para forjar uma identidade local. Na baía do Iguape, pode-se perceber uma densidade social entre os pescadores e marisqueiros, definida por Duvignaud (apud SANTOS, 2008, p. 318) segundo a copresença dos homens em um local cujas relações são movidas "pela afetividade e pela paixão, e levando a uma percepção global, 'holista', do mundo e dos homens".

Todavia, como ressalta Santos (2008), no período do meio técnico-científicoinformacional, o espaço é permeado pelo processo contraditório do Mundo, que se expressa no lugar, imprimindo a este uma lógica interna ao mercado que se exerce como lógica externa ao lugar. Ignorando a opinião da população local, os agentes hegemônicos apenas buscam no lugar as condições para realizar seus objetivos de produção e/ou circulação com maior produtividade. $\mathrm{O}$ autor explica a luta que se desenrola para o uso do espaço entre empresas e instituições hegemônicas em situação ativa, e outros agentes sociais em posição passiva. A lógica exógena do Mundo, quando se impõe ao lugar, tende a excluir mais ainda os setores desfavorecidos, menos modernos e informados, provocando uma desterritorialização dos mesmos. Esse caso se configura em virtude da aceleração do tempo e da amplitude dos fluxos, em populações geograficamente fixas, ou seja, surge uma desterritorialização de populações locais marginalizadas das decisões sobre o espaço, embora elas tenham construído, no curso da história, laços fortes de identidade com o lugar. A desterritorialização, nas suas dimensões econômica, política e cultural, ocorre, neste caso, na (e por causa da) imobilidade em favor da territorialização de grandes empresas funcionando em redes que expressam a sua mobilidade (HAESBAERT, 2004). As populações excluídas perdem controle sobre o espaço por elas historicamente ocupado, não garantem seus direitos fundamentais de cidadania e podem perder também sua identidade sociocultural, quando seu espaço é alterado. Essa situação se revela especialmente aguda quando se trata de populações tradicionais, que vivem em estreita comunhão com a natureza. Mas é também em escala do lugar que se pode encontrar o acontecer solidário em que horizontalidades ocorrem, defrontando-se e afrontando verticalidades.

Diante da conflituosidade latente da diversidade de usos do solo e da água na zona costeira, e da disparidade de forças entre agentes sociais, tal como acima citado, o planejamento e a gestão pelo Estado são cruciais. No litoral brasileiro, existem unidades de conservação (UC) de vários tipos no Oceano Atlântico, como parques nacionais marinhos, e no continente, variando de $\mathrm{APP}^{3}$ a reservas extrativistas (Resex). A diferença das áreas de preservação permanente para as de uso sustentável incluem as populações locais, no objetivo de proteção ambiental graças ao caráter tradicional das mesmas, implicando em um profundo conhecimento do meio natural e uma consequente sustentabilidade dos modos de vida. É o caso, em especial, das Resex, onde as populações são organizadas de modo a cogerenciar seu território com o órgão ambiental, o Instituto Chico Mendes de Conservação da Biodiversidade (ICMBio). Os extrativistas participam da gestão, fundamentados nos seus saberes ambientais acumulados e transmitidos pela oralidade e experiências, ao longo de gerações.

Todavia, as políticas públicas mostram contradições internas, como é o caso da implantação, pelo governo estadual, de um polo naval em uma Resex marinha federal. O exemplo mostra claramente o papel paradoxal do Estado, na encruzilhada entre um discurso pregando a proteção ambiental, visando reduzir as pressões internas e externas no campo ecológico-político, e ações de promoção do dito desenvolvimento econômico, em detrimento da citada proteção ambiental, embora vários projetos utilizem o discurso de desenvolvimento sustentável. Esse problema é aguçado quando os agentes sociais tradicionais não dispõem de título de propriedade. As Resex deveriam ser mais protegidas, uma vez que são registradas como concessão real de uso coletivo. Mas, a prática demonstra que elas enfrentam, malgrado seu estatuto legal, questões fundiárias e de uso dos recursos naturais não resolvidas, que se traduzem em conflitos. 


\section{A RESERVA EXTRATIVISTA BAÍA DO IGUAPE}

A Reserva Extrativista Baía do Iguape se estende sobre 8.117,53 hectares, sendo 2.831,24 ha de manguezal e 5.286,29 ha de águas internas brasileiras (Figura 1). Sua criação expressa o reconhecimento do valor ecológico que a área contém, ou seja, uma valoração de tipo econômico-ecológico, mas igualmente a valorização consagrada pelas populações locais para as quais o manguezal representa o lócus do seu habitat e de seu trabalho, assim como um lugar repleto de significados simbólicos, o que leva à consideração sobre a incomensurabilidade dos valores, como salientam autores como Martínez Alier (2007).

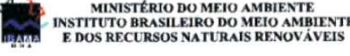

Reserva Extrativista Marinha Baia do Iguape / BA

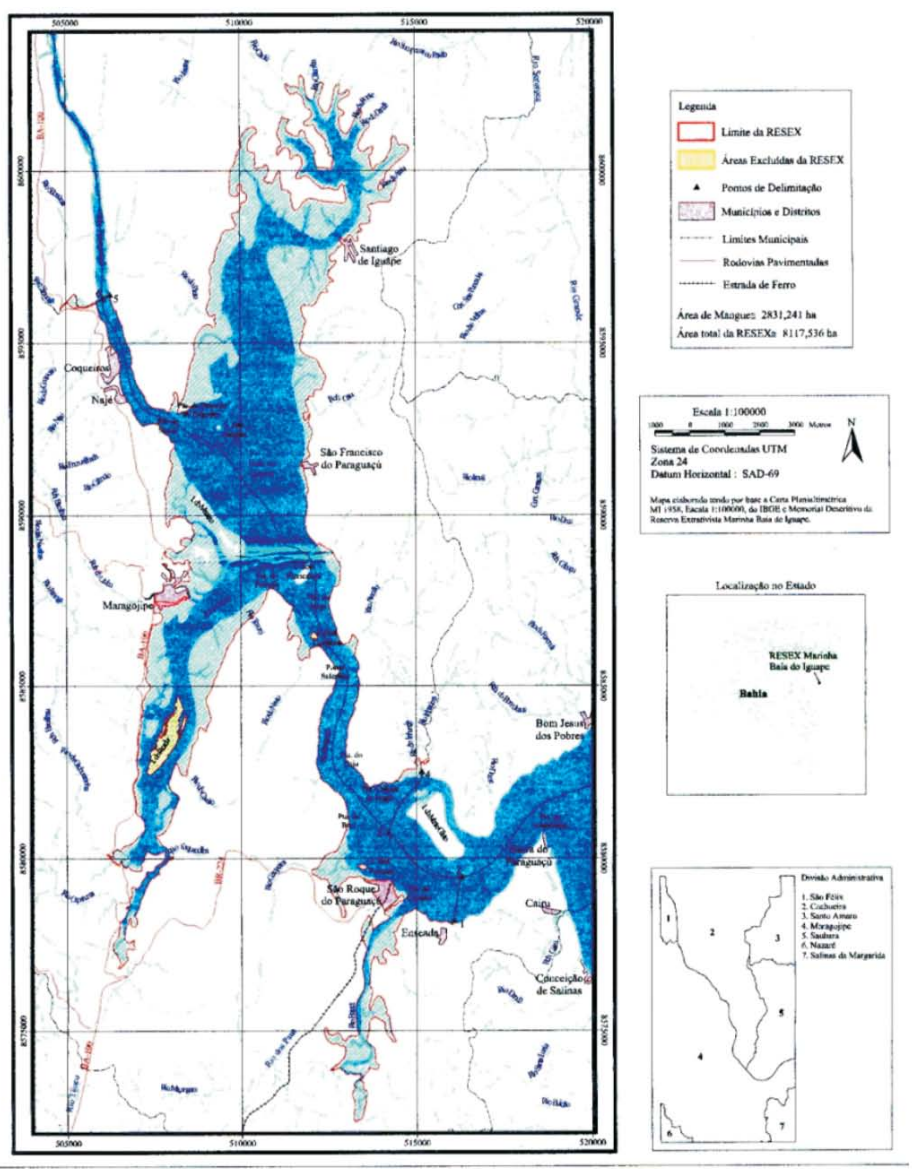

Figura 1. Reserva extrativista Baía do Iguape.
O manguezal representa um ecossistema costeiro extremamente importante para a vida, em razão de suas diversas funções ecológicas. Situado preferencialmente na foz de um rio, estuário ou até em linha de costa, o manguezal cumpre muitas funções, tais como retenção de sedimentos e matéria orgânica, proteção das margens, berçário e viveiro de diversas espécies da ictiofauna, como também de espécies de anfíbias e de aves. Ele ainda se revela importante para a conservação de recifes de coral, localizados a dezenas de quilômetros dos mangueais. Essa riqueza, expressa entre as mais altas produtividades primárias, do ponto de vista biológico ${ }^{4}$, serve de base para as práticas sociais e o consequente sustento de numerosas populações costeiras, no mundo e no Brasil, tal como é o caso na Baía do Iguape. Nela, encontram-se 20 comunidades $^{5}$, agrupando cerca de 20.000 pessoas vivendo da pesca artesanal, segundo os agentes do Conselho Pastoral dos Pescadores (CPP), que trabalham na região do Recôncavo baiano ${ }^{6}$.

A pesquisa de campo se desenvolveu em várias comunidades, sendo algumas de caráter relativamente urbano, nas sedes de município e de distritos - Maragojipe, Nagé, Coqueiros e São Francisco do Paraguaçu, no município de Maragojipe; e São Francisco do Paraguaçu e Santiago do Iguape, no município de Cachoeira - e outras de caráter nitidamente rural, no município de Cachoeira - Caonje, Calolé, Imbiara, Dendê, Engenho da Ponte e Engenho da Praia.

A Resex marinha abriga a atividade de pesca artesanal, que se caracteriza, dentre outros fatores, por capturas multiespécies. De fato, peixes variados, de água salobra e salgada, compõem a dieta e a base da renda dos extrativistas, assim como crustáceos, como camarão, e moluscos diversos (sururu, ostra, sarnambi etc.). A pesca desempenha um importante papel, seja pelo consumo direto, seja pela renda gerada pela venda das capturas.

Na baía do Iguape, o caráter artesanal da pesca se evidencia também por um grau de tecnologia extremamente simples: os apetrechos são variados, indicador da necessária polivalência na pesca imposta por capturas que não fornecem uma renda substancial. Artes fixas, como as gamboas, ou móveis, como as redes de náilon grosso, formam os instrumentos dos pescadores nas suas variadas estratégias. As mulheres se voltam preferencialmente para a atividade de mariscagem, ou seja, de coleta de mariscos diversos em áreas de manguezal ou em bancos de areia. Elas geralmente não dispõem de embarcações e se locomovem até os locais de captura

\footnotetext{
Segundo Messiac (2001), a produtividade atinge 8.800 kilocalorias $/ \mathrm{m}^{2} /$ ano.
}

Segundo o IBAMA.

O cadastramento dos extrativistas ainda não foi realizado, impedindo fornecer dados precisos. 
caminhando ou embarcando em canoas, quando os pescadores lhes cedem espaço. Os pescadores dispõem, na sua maioria, apenas de canoas a remo, eventualmente movidas a vela, quando o vento permite. Os barcos motorizados são uma exceção na Resex; algumas comunidades organizadas em torno do Movimento da Pesca e do Conselho Pastoral dos Pescadores (CPP) obtiveram, através de projetos, canoas de fibra de vidro, motorizadas, utilizadas de forma comunitária por grupos previamente definidos. As aquisições visam uma economia do esforço manual e uma maior agilidade nas expedições de pesca. Mas, a predominância da canoa a remo, aliada à ausência de tecnologia, implica, portanto, em um raio de autonomia limitado à própria baía do Iguape, com exceção de pescadores de São Roque do Paraguaçu, que se aventuram, às vezes, além da chamada barra, na Baía de Todos os Santos. No entanto, não se observa deslocamentos mais longos, como se pode observar em outros segmentos da costa brasileira.

Com esses meios de produção, a renda oriunda da atividade pesqueira permanece em níveis muito modestos. O censo do IBGE de 2000 mostra a predominância, nas áreas de estudo, de rendas baixas - sendo todas as categorias profissionais confundidas - ao indicar que dois terços dos recenseados afirmam ganhar até 2 salários mínimos. Somado a isso, cerca de $23 \%$ não declaram rendimento mensal, dando uma ideia do quadro geral de pobreza. A Figura 2 ilustra o levantamento efetuado, em campo, da renda média da pesca - incluindo a mariscagem - na estiagem, período de maiores capturas, mas de preços mais baixos do que na estação chuvosa.

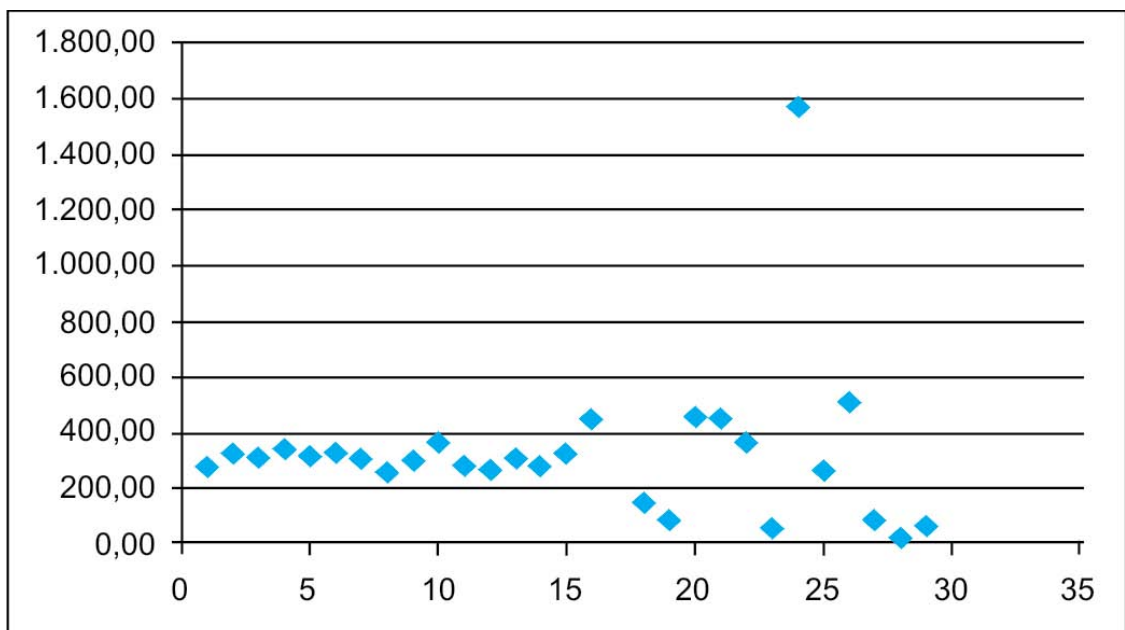

Figura 2. Renda mensal média obtida na pesca (em reais).

Fonte: dados de campo.
Percebe-se que os levantamentos efetuados junto a pescadores e marisqueiras dão resultados oscilando entre 30 e 650 reais mensais, salvo um valor extremo próximo de 1.600 reais. A modéstia da renda deve ser ainda avaliada à luz do tamanho das famílias. Nas áreas rurais, apresentem padrões elevados, sendo a metade das famílias com 4-5 filhos. A pobreza não se torna miséria devido ao aporte à dieta dos produtos da pesca e da agricultura, no caso das comunidades rurais. Como costumam dizer os entrevistados: "Só morre de fome quem é preguiçoso". Todavia, as condições de trabalho e de moradia completam um quadro social desfavorecido, em particular nas áreas rurais, haja vista a condição das casas (muitas feitas de taipa, com poucos móveis e cômodos) e dos serviços básicos deficientes ou inexistentes, como é o caso do acesso à água para consumo, deficiente nas sedes urbanas e inexistente em quase todas as áreas rurais.

A importância social da pesca apresentou um aumento relativo nas últimas décadas, em razão do declínio de atividades econômicas, como a indústria de charutos, que chegou a empregar até 5.000 funcionários no município de Maragojipe. A crescente concentração fundiária nas mãos de grandes fazendeiros também compeliu as populações voltarem-se para outras atividades, uma vez que as terras disponíveis para a agricultura de subsistência e para o extrativismo vegetal diminuíram e que as fazendas privilegiam o (pouco) emprego a pessoas de outros municípios. Na Baía de Todos os Santos, a drástica diminuição, na década de 1990, da extração de petróleo iniciada em 1950, constituiu mais um fator que levou os habitantes da região a migrar para a região metropolitana de Salvador ou a se dedicar à atividade pesqueira (PROST, 2007). Enfim, o deslocamento do eixo principal de fluxos, provocado pela construção da rodovia BR 324 na década de 1930, em detrimento da via férrea que ligava Cachoeira e São Félix a Salvador, contribuiu mais ainda para frear a economia regional. Registra-se uma atividade industrial no distrito de São Roque do Paraguaçu, como a instalaçãode um canteiro de plataforma da Petrobras, na década de 1970, em que nativos também foram empregados. Todavia, sem encomendas, e, portanto, sem atividade durante uma década, a geração de empregos desvaneceu. Hoje, o canteiro está novamente ativo, mas sua atividade irregular não proporciona uma segurança profissional aos moradores locais, além de privilegiar também migrantes de outros municípios com a qualificação necessária.

Em face desse quadro econômico, as soluções encontradas pelas populações locais foram principalmente duas: migração e pesca. Quarenta por cento dos 
entrevistados afirmaram que algum parente tinha migrado. Contudo, observa-se uma diversidade de migrações, com destaque para uma maioria de deslocamentos de até um ano (Figura 3). As alternativas de trabalho servem, portanto, como alternativas passageiras e não verdadeiras.

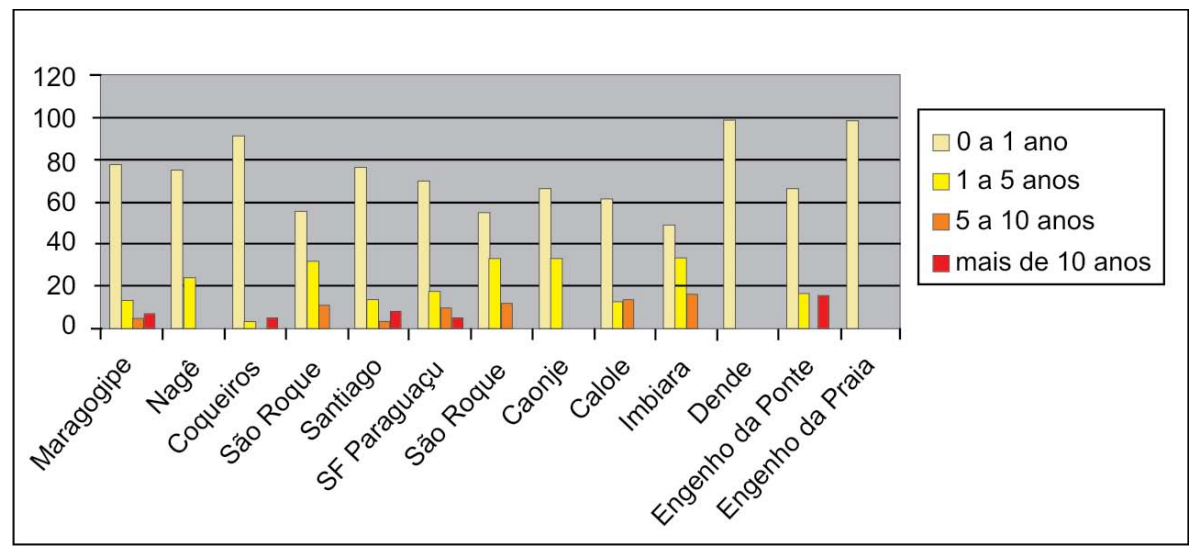

Figura 3. Percentual do tempo passado fora da comunidade, pelos migrantes das famílias. Fonte: Pesquisa de campo.

Para quem fica na região da baía do Iguape, a solução privilegiada foi, primeiramente, de se orientar para a exploração dos recursos pesqueiros, acentuando a pressão demográfica sobre os mesmos, contribuindo, em parte, para a evolução negativa do esforço de pesca. Convém lembrar, todavia, os fatores estruturais que contribuíram a ampliar os esforços de pesca acima elencados, além de outros fatores, como a implantação da central hidrelétrica na barragem Pedra do Cavalo, que prejudica a pesca (PROST, 2007).

Como colocado na parte dedicada à zona costeira, para ordenar a ocupação e o uso do espaço é preciso que um agente público, o Estado, intervenha de modo a prevenir ou resolver conflitos. $\mathrm{Na}$ área de estudo, no intuito de proteger o ambiente natural e cultural da Báa do Iguape, uma Resex marinha criada por decreto, em 2000. A criação expressa o reconhecimento do valor ecológico da área, mas também o das populações tradicionais e, enquanto tal, portadoras do direito de fixar sua territorialidade. As populações tradicionais são definidas pelo órgão ambiental federal como grupos históricos que exercem determinadas práticas sociais de baixo impacto ambiental sobre a natureza, há pelo menos duas gerações. No Brasil, vários espaços ocupados por diversas populações tradicionais, tais os seringueiros, as quebradeiras de coco babaçu, os pescadores artesanais, as comunidades quilombolas, indígenas ou de fundo de pasto, dentre outras, fazem uso secular de territórios de uso comum, contando com regras coletivas de manejo construídas ao longo de um tempo histórico, com baixa ou densidade técnica quase nula.

Convém ressaltar aqui a observação de Almeida (2004) sobre outro componente da definição de populações tradicionais - além do histórico e da relação com a natureza - autorizado a partir da Constituição de 1988 e confirmado com a ratificação, em 2002, da Convenção 169 da OIT, que reside na autoidentificação. Esse marco provém não apenas de avanço, na esfera dos poderes políticos, mas também de uma história de luta para o reconhecimento de garantia de apropriação de seus territórios por grupos tradicionais diversos, entre os quais a aliança dos seringueiros do Acre e dos indígenas ganhou destaque internacional. Em outras palavras, o termo de tradicional não se refere apenas à história, mas "incorpora as identidades coletivas redefinidas situacionalmente numa mobilização continuada" (ALMEIDA, 2004, p. 10).

Essa situação é manifesta na Baía do Iguape, onde, após uma visita de exposição do IBAMA sobre reserva extrativista, um grupo de pescadores se mobilizou para a criação da Resex marinha. Apesar disso, a UC federal permaneceu praticamente sem concretude durante cinco anos, pois o conselho gestor só foi implantado em 2005, revelando a falta de prioridade do IBAMA nos assuntos costeiros. Assim sendo, os pescadores formaram o grupo pró-Resex, com apoio de segmentos da sociedade civil organizada, para pressionar o IBAMA a deslanchar o processo de constituição da esfera decisória da UC. De fato, o Sistema Nacional de Unidades de Conservação (SNUC) prevê a criação de um Conselho Deliberativo nas Resex, presidido pelo órgão ambiental federal - hoje ICMBio - para cogerir a UC com sua população extrativista. O estatuto de reserva extrativista se destaca em relação com as demais UCs, até as de uso sustentável, por serem administradas por uma instância de decisão deliberativa, contribuindo para o avanço da cidadania. O Conselho é formado por uma metade de representantes dos extrativistas e outra metade formada por órgãos públicos e demais instituições do setor privado e do terceiro setor, atuantes na área da Resex e do seu entorno ou usuárias dos recursos hídricos. Os extrativistas compõem a maioria absoluta no Conselho e detêm a vice-presidência.

Nas UCs de uso sustentável, com a diversidade dos grupos tradicionais, evidencia-se uma diversidade de usos dos espaços ocupados, podendo aliar espaços de uso comum dos recursos naturais e apropriação individual de bens. É o que se 
nota na Baía do Iguape entre os pescadores lavradores, que fazem uso de pequenas roças para a agricultura de subsistência e usam de forma coletiva espaços - cada vez mais raros - de extrativismo vegetal, além de pescar e mariscar na própria Baía do Iguape. Como os meios aquáticos são, por excelência, espaços de acesso livre, as regras de uso comum são especialmente importantes para evitar a tragédia dos comuns. As regras consuetudinárias são traduzidas em normas jurídicas sob formas diversas, indo de acordos de pesca a planos de uso a serem elaborados no âmbito de uma Resex. Com um plano de uso aprovado, toda pessoa pertencente a uma Resex ou não, deve respeitar as regras de uso dos recursos naturais no perímetro da referida UC. O plano de uso objetiva garantir a sustentabilidade na exploração dos recursos naturais, preservando, por conseguinte, o modo de vida do grupo social que deles tira seus meios de (re)produção social. Ele torna norma reconhecida por lei, as práticas sociais sustentáveis de manejo dos recursos. Além desta meta, o Conselho Deliberativo exerce uma função de controle social sobre os acontecimentos em curso ou projetados, dentro da Resex ou na área do seu entorno $(10 \mathrm{~km})$. Isso significa que qualquer ação deve ser preliminarmente submetida à apreciação do Conselho, quer seja de mera pesquisa, quer seja de intervenção mais concreta sobre o meio natural ou a organização do território.

A partir de 2007, a Resex Baía do Iguape ganhou um coordenador local do ICMBio, impulsionando uma maior regularidade das assembleias para se pensar o planejamento e a gestão da Unidade de Conservação. Representa, assim, um avanço concreto, embora persistam muitas dificuldades, em consequência de uma mobilização freada por limitação de recursos financeiros e materiais, e problemas locais de gestão. A participação dos extrativistas da Resex é fundamental por várias razões intrínsecas, mas também para melhor garantir os objetivos da Resex diante das ações de atores externos, tal como é o caso da central hidrelétrica da barragem Pedra do Cavalo, no rio Paraguaçu, ou do projeto em curso, de implantação de ampliação de canteiro naval em São Roque do Paraguaçu.

\section{POLÍTICA DO GOVERNO: A AMPLIAÇÃO DO CANTEIRO NAVAL}

O setor da construção naval, concentrado nas regiões costeiras, detém uma importância estratégica para a defesa nacional, interessante, portanto, para o governo federal. Além disso, é conhecido por gerar milhares de empregos diretos e indiretos, através de contratos bilionários e por engendrar repercussões sobre outros setores econômicos, como a siderurgia e as indústrias elétricas e mecânicas. Segundo dados do governo da Bahia, a indústria naval mundial fatura em média 120 bilhões de dólares por ano. Nesses últimos anos, as demandas interna e externa têm aumentado e devem seguir essa tendência, incentivando os planejadores a pensar na ampliação do complexo naval no mundo e no Brasil. De fato, em escala nacional, com a descoberta da camada de petróleo na área do "pré-sal", a expectativa anunciada pela Petrobras é de encomendar um pacote com dezenas de navios para transporte de óleo e derivados, de embarcações de apoio marítimo e de plataformas ${ }^{7}$. Tendo em vista a insuficiente capacidade de construção naval na região Sudeste, outras regiões estão sendo contempladas nos projetos estaleiros e canteiros, como é o caso do Sul e do Nordeste.

$\mathrm{Na}$ Bahia, o governo tomou a iniciativa de planejar um projeto de ampliação de canteiro naval em São Roque do Paraguaçu, iniciado como um projeto de polo naval, com canteiro e estaleiro, inserido em um programa mais amplo chamado Acelera Bahia. Esse fomento ao desenvolvimento econômico se enquadra também em uma conjuntura favorável, com o Plano de Aceleração do Crescimento (PAC), lançado pelo governo Lula. Desde o primeiro mandato, o presidente da república tinha se posicionado em favor de investimentos públicos para dinamizar a construção naval. O programa Acelera Bahia foi elaborado no intuito de atrair novos investimentos para o estado.

A Bahia goza de vantagens locacionais inegáveis, com quase mil quilômetros de costa, em uma localização central em relação ao país e ao continente. A Baía de Todos os Santos, na qual está inserida a baía do Iguape, possui mais vantagens por ser umas das maiores baías do mundo, com $1.052 \mathrm{~km}^{2}$ de águas protegidas e profundas. Por isso, desde as décadas de 1970 e 1980, cinco polos navais foram implantados nela, sendo três em Aratu e um em São Joaquim, na Baía de Todos os Santos, e o maior em São Roque do Paraguaçu, no sul da baía do Iguape. No atual projeto, três áreas foram estudadas para receber o futuro polo. Em audiência pública na Câmara Legislativa em Salvador, foi apresentada, de forma breve, a justificativa da opção pela localização preferencial em São Roque do Paraguaçu, em relação aos dois outros locais estudados: Aratu e Madre de Deus. Dentre os argumentos, foram destacados o profundo calado existente em São Roque (10 metros), permitindo a entrada de navios de grande porte, a ausência de 
impedimentos ambientais e a fraca circulação de embarcações - o que se entende bem pelo fato de estar afastado dos portos de Salvador e Aratu, e de se tratar de uma reserva extrativista (!). Todavia, a simples vantagem locacional não é suficiente para garantir a atração de investimentos privados. Para tanto, o poder público deve também aplicar políticas para ganhar a preferência em relação a outros Estados, fenômeno conhecido na geografia como guerra dos lugares.

Destarte, o governo se encarrega de viabilizar a instalação do polo, de várias formas. Estima-se que o investimento total seja de cinco bilhões de reais, sendo quatro por empresas e um por parte do governo, sob forma da implantação de infraestrutura. Na conjuntura atual, a infraestrutura industrial existente em São Roque é vista pelo governo e várias empresas como um trunfo para uma ampliação que permita uma atividade contínua, graças à instalação de um dique seco, para permitir a construção, o reparo e a manutenção de plataformas e de navios. Os investimentos privados recebem incentivos fiscais, no âmbito do projeto Programa Estadual de Incentivos à Indústria Naval (PRONAVAL), instituído pela Lei $\mathrm{n}^{\circ}$ 9.829, de 2005, e regulamentado pelo Decreto ${ }^{\circ} 11.015$, de $2008^{8}$. Por fim, a criação anunciada de mais de 10.000 empregos para os jovens da região, em uma primeira fase do projeto, requer, contudo, qualificações específicas. Os investidores solicitam que o Estado proporcione as condições de formação do público visado. Os prefeitos da região também estão interessados nisso para evitar o que aconteceu até então no canteiro de São Roque do Paraguaçu, que contratou essencialmente pessoas de fora, por falta de qualificação dos habitantes locais. Assim sendo, em março de 2009, foram iniciados cursos de três meses do Programa de Mobilização da Indústria Nacional de Petróleo e Gás Natural (PROMINP), realizados através de parceria entre o governo estadual, a Federação de Indústrias da Bahia (FIEB), o SENAI e o SEBRAE?. Os cursos são gratuitos e distribuem bolsas para 1.200 jovens de municípios do chamado Recôncavo sul: Maragojipe, Salinas, da Margarida, Nazaré das Farinhas, Santo Antonio de Jesus, Cachoeira, São Félix do

8 Disponível em: <http://www2.casacivil.ba.gov.br/NXT/gateway.dll/legsegov/ decnum/decnum2008/decnum2008abr/decn200811015.xml?fn=document-frame. $\mathrm{htm} \$ \mathrm{f}=$ templates $\$ 3.0>$. Acesso em: 10 ago. 2009. Cita-se: i) a dilação de prazo de 72 meses para o pagamento de $98 \%$ do saldo devedor mensal do ICMS decorrente das operaç̃es próprias resultantes do investimento previsto no projeto beneficiado pelo PRONAVAL, ii) a dispensa do pagamento do imposto incidente nas operações com concreto, cimento, aço e bens do ativo destinados à construção e reparo de dique seco por empresa habilitada ao PRONAVAL e iii) o deferimento do lançamento e pagamentos do ICMS relativos às aquisições de ativo fixo.

Serviço Nacional de Aprendizagem Industrial e Serviço Nacional de Apoio às Pequenas e Médias Empresas.
Paraguaçu, Itaparica, Vera Cruz e Jaguaripe. Como a escolha dos jovens para a capacitação não atende o conjunto de perspectivas levantadas nas comunidades, vários jovens pagam os cursos, aumentando a oferta de mão de obra potencial.

A Secretaria da Indústria, Comércio e Mineração (SICM) já assinou protocolos de intenções para a construção de três estaleiros na baía do Iguape, sendo um com a empresa baiana Odebrecht, outro com a empresa Estaleiro da Bahia S.A., uma jointure da OAS, Setal e Piemonte e um terceiro com a UTC Engenharia. O objetivo do polo é fornecer os seguintes produtos: sondas de perfuração, plataformas de produção de petróleo, navios FPSO (Floating, Production, Storage and Offtake) e navios de apoio a petroleiros. Segundo a CUT ${ }^{10}$, com a construção de dois navios ou duas plataformas por ano para atender as demandas da Petrobras, o canteiro-estaleiro movimentaria cerca de dois bilhões de reais, o que aparece como uma perspectiva muito lucrativa para o setor privado e vantajosa para o poder público - especialmente se levamos em conta as eleições de 2010 ... Este afirma uma forte geração de empregos, o que é visto pela população não pesqueira dos municípios vizinhos como uma boa oportunidade, haja vista $\mathrm{o}$ declínio econômico que a região conheceu nas últimas décadas.

\section{POTENCIAIS IMPACTOS NEGATIVOS - A CONFLITUOSIDADE ENTRE DOIS MODELOS DE DESENVOLVIMENTO}

O polo naval é, portanto, apresentado como uma excelente oportunidade para redinamizar a economia no Recôncavo sul, além de ter repercussões positivas sobre a siderurgia na Bahia. Todavia, se a população não pesqueira do município de Maragojipe tende a aprovar o projeto, não se pode dizer o mesmo das populações pesqueiras da Resex, nem de várias organizações sociais e ambientalistas e de parte da comunidade universitária, como atestam os questionamentos feitos em assembleia do conselho deliberativo da Resex aos representantes do governo e das empresas e em seminários organizados em universidades ${ }^{11}$.

O anúncio de empregos que tanto atrai parte da população é questionável, à luz de eventos passados ocorridos na região costeira. De fato, empreendimentos

10 Disponível em: <http://www.cut.org.br/content/view/11434/170>. Acesso em: 10 ago. 2009.

${ }^{11} \mathrm{O}$ projeto foi apresentado sumariamente na assembleia do conselho, no dia 16 de outubro de 2009. Dois seminários foram organizados na UFBA, em 2009; no dia 18 de março na Escola Politécnica, e no dia 24 de abril, no Instituto de Geociências e na UCSal, no dia 27 de novembro. 
como a barragem e central hidrelétrica Pedra do Cavalo ou a indústria petrolífera em municípios como Madre de Deus ou São Francisco do Conde mostram o quanto a população local é marginalizada no mercado de trabalho desses grandes empreendimentos. Em pesquisa realizada em Madre de Deus, as populações pesqueiras do município sentiram uma diminuição sensível das capturas desde o início das atividades industriais, por razões diversas, elencadas a seguir: poluição por vazamentos de óleo e derivados, obstrução de canal na maré baixa por causa da instalação de dutos, redes rasgadas nas estruturas de perfuração, dentre outros fatores. Nessas condições, pescadores e marisqueiras enfrentam muitas dificuldades de sobreviver apenas da pesca. Embora procurem se empregar na indústria de petróleo, muitos se queixam da precariedade da estabilidade do trabalho, além da necessidade de investimento prévio para adquirir as qualificações necessárias. Nem os royalties que as prefeituras recebem da Petrobras se traduzem em benefícios econômicos e sociais para esse segmento da população.

As perspectivas tampouco são promissoras na Baía do Iguape. Em visita na Enseada ${ }^{12}$ - comunidade mais próxima de São Roque do Paraguaçu e do futuro canteiro naval-, marisqueiras relataram que dos doze jovens que se candidataram a cursos de formação profissional, apenas três foram selecionados. Outros pagaram um curso, de forma a concorrer às futuras vagas de trabalho.

Além disso, do ponto de vista social, o anunciado desenvolvimento sustentável propalado pelo governo estadual corre fortemente o risco de se traduzir, na realidade, em efeitos danosos para as populações, dos pontos de vista social e cultural. De fato, em excursão organizada pelo Instituto de Gestão das Águas e Clima (INGÁ), em agosto de 2009, no âmbito do projeto Iguape Sustentável, foram realizados encontros com representantes de várias comunidades ribeirinhas contempladas no projeto. Um secretário da prefeitura de Maragojipe informou à equipe do Iguape Sustentável que a perspectiva de indústria naval já desencadeou uma especulação imobiliária na sede municipal e fundiária no entorno da baía. As lideranças sociais também confirmaram que as grandes empresas interessadas no polo estão comprando terras de fazendeiros para futuros empreendimentos. Paralelamente, comunidades organizadas na resistência aos grandes projetos industriais sofrem empecilhos na concretização de certos projetos que lhes trariam melhoria na vida cotidiana, como o projeto de extensão elétrica até a comunidade de Salaminas ${ }^{13}$.

\footnotetext{
12 Visita efetuada em dezembro de 2009.
}

13 Destaca-se o caso da comunidade de Salaminas, que ganhou financiamento por um edital lançado pelo órgão estadual Bahia Pesca, para um projeto elaborado pelo Movimento da
Outros efeitos sociais decorrentes do projeto do governo são também previsíveis, como o aumento das migrações, o que deve aguçar a questão de moradia precária - incluindo a habitação como o saneamento básico -, a deficiência em serviços básicos (educação e saúde), o tráfico de drogas já presente no município, a delinquência e a prostituição. Essas consequências foram observadas em municípios próximos, que sofreram profundas mudanças após uma ampla implantação industrial, como comprovam os testemunhos de integrantes do Movimento da Pesca no II Encontro das Resex Marinhas da Bahia, realizado em Maragojipe, em outubro de 2009.

Percebe-se desde já que as carências de moradia, especialmente de saneamento, deverão contribuir para o aumento de despejo de esgoto in natura no manguezal, considerado pelos próprios extrativistas como um "supermercado vivo". Em estudo anterior sobre os impactos de atividades humanas na região da baía (MONTEIRO; PROST, 2009), relatou-se a degradação do meio ambiente, notadamente por desmatamento de vertentes originado pela pecuária e pela extensão urbana da sede de Maragojipe. Com a chegada de novos habitantes, estima-se uma consequente urbanização espontânea, uma vez que a Petrobras construiu em São Roque uma vila residencial para abrigar 200 funcionários e uma vila de alojamentos para hospedar apenas 1.000 trabalhadores das empresas contratadas para a ampliação do canteiro $^{14}$. Com isso, é de se esperar uma ampliação e agravamento da mudança de processos morfogenéticos para processos pedogenéticos, expressados por erosão das vertentes e assoreamento da baía e cursos d'água. $\mathrm{Na}$ área prevista do empreendimento, áreas de manguezal devem ser retiradas, infringindo a lei ambiental em um total descompasso com o argumento alegado para justificar a extensão de uma linha elétrica como citado acima. Também serão desmatadas áreas cobertas por Mata Atlântica e restinga. Embora o sítio tenha sido escolhido em nome de um calado profundo, as empresas contratadas alegam a necessidade de dragagem e planejam o aterramento de parte do canal, implicando em profundas alterações no meio aquático e prejudicando a fauna presente em todos níveis de profundidade d'água (superfície, coluna d'água e fundo). Os

Pesca, que inclui a aquisição de equipamentos para produção, estocagem e beneficiamento da pescaria, assim como para consolidação da organização social (ex: freezers, geladeira, televisor, leitor de DVD, etc.). O uso desses equipamentos está impossibilitado até hoje por falta de energia elétrica, cujo projeto de extensão está impedido pelo IBAMA, sob pretexto de evitar o corte de dois pés de árvores de manguezal para a instalação de postes. O argumento soa falacioso se comparado com as áreas de manguezal que vão ser desmatadas para a extensão do canteiro de São Roque.

14 Disponível em: <http://www.tnpetroleo.com.br/noticia/19600/Petrobras+revitaliza+ind\%C 3\%BAstria+naval+da+Bahia $>$. Acesso em: 11 jul. 2009. 
investidores declaram que a atividade não polui, mas a existência do canteiro em São Roque já evidencia a concentração de ferro na água, o que propicia o agravamento de fenômeno de maré vermelha, tal como ocorreu em 2007, encadeando uma alta mortandade de peixes. Segundo o professor de biologia Everaldo Queiroz, estudioso da Baía de Todos os Santos, novos fenômenos como esse podem ocorrer, inclusive com espécies letais a humanos. O relatório organizado por ele sobre o projeto do polo ${ }^{15}$ conclui que entre os impactos ambientais esperados, contam ainda com os efeitos das construções projetadas, que vão atingir as áreas de rochas sedimentares que armazenam águas subterrâneas. Last but not least, o projeto vai provocar "sérios impactos em águas jurisdicionais tombadas por decreto presidencial na condição de santuário para os mamíferos aquáticos”"16. A análise do EIA-RIMA tende a minimizar os efeitos negativos da atividade sobre a natureza, com uma projeção limitada da "área de influência direta", uma relativização dos impactos ambientais, um reducionismo do conceito de territorialidade e uma visão pessimista sobre a sustentabilidade da pesca artesanal. Os efeitos negativos são surpreendentes, quando comparados aos efeitos positivos, entre os quais as considerações econômicas (de "alta significância”) predominam (Figuras 4 e 5).
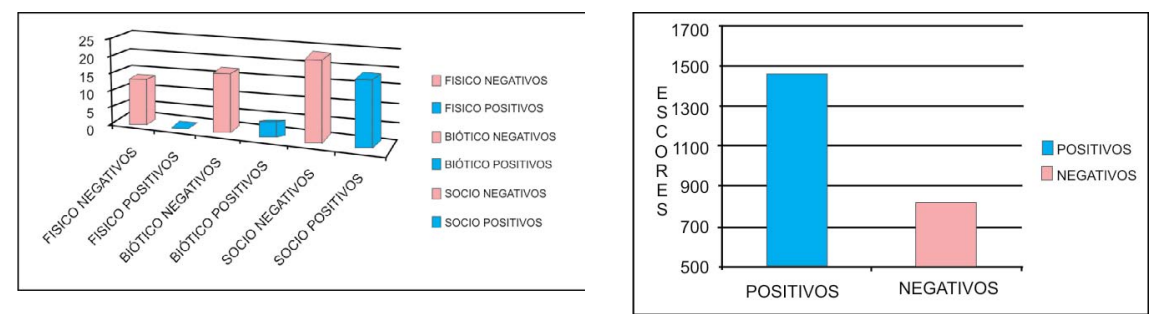

Figura 4. Distribuição dos impactos positivos e Figura 5. Comparação dos escores cumulativos negativos (RIMA, 2009). dos impactos negativos e positiva de média e alta significância (RIMA, 2009).

Apesar dos projetos de cunho social e ambiental apresentados pelo complexo de empresas para legitimar o empreendimento, afeta-se diretamente as condições de trabalho das populações pesqueiras em área de manguezal, prejudicando as condições socioeconômicas de vida das localidades do entorno da baía. São, assim, ameaçadas as práticas dessas populações, que integram uma cultura própria, mas desprezada por uma sociedade moderna à busca de crescimento econômico ilimitado.

15 Polo naval - uma proposta que não pertence a todos nós. Apresentado em seminários: 18.03.09, na Escola Politécnica da UFBA, e 24 de abril no Instituto de Geociências da UFBA.

16 Relatório da apresentação do Prof. Queiroz nos seminários realizados na UFBA e na UCSal.
O governo de Estado afirma adotar uma metodologia incluindo a participação das populações. Nada mais inverídico do que essa afirmação. Como foi informado anteriormente, as Resex são gerenciadas por lei, por um conselho deliberativo, o que significa que qualquer intervenção dentro do seu perímetro deve passar por aprovação prévia. Ora, uma audiência pública realizada em Maragojipe, em dezembro de 2008, a pedido dos ministérios públicos federal e estadual, contou com uma imensa maioria de participantes contrária ao empreendimento. Contudo, a situação é agravada por uma mobilização contra o projeto, que se apresenta fragmentada e relativamente fraca diante dos interesses e ações dos governos estadual e municipal. Apenas as comunidades organizadas no seio do Movimento da Pesca se opõem abertamente ao projeto, uma vez que as autoridades seduzem as populações através da promessa de dinamizar a economia local, gerando emprego e renda.

Esta situação em curso nos remete a deduzir a desterritorialização das populações locais, em particular as extrativistas, uma vez que elas perdem controle sobre o seu espaço tradicional de apropriação material e simbólica de seu território, delimitado em reserva extrativista a partir de 2000. A lógica exógena do capital se impõe ao lugar, sem levar em consideração a soma dos efeitos negativos para as populações pesqueiras e de pescadores-lavradores. Utiliza-se o discurso do desenvolvimento sustentável para retirar das populações o poder sobre seu território. Estas chegam, portanto, a ser ameaçadas de desterritorialização, apesar - ou por causa - de sua imobilidade geográfica. Frente a elas, figuram atores econômicos que funcionam em rede e usufruem de uma mobilidade muito maior. O sinal disso é a reflexão sobre uma transferência do projeto - ou parte dele - para o estado do Rio de Janeiro, por parte do consórcio Setal/OAS, caso o projeto encontre dificuldades na aprovação do licenciamento ambiental ${ }^{17}$. O que as empresas requerem é a acessibilidade ao local do projeto, o que é garantido pelo Estado no afã de atrair investimentos privados. Por sua vez, os pescadores não gozam da mesma capacidade de se locomoverem para exercer suas práticas. Isso é particularmente o caso na baía do Iguape, com a grande maioria das embarcações constituída de canoas a remo. A situação futura na baía do Iguape, no caso do projeto de polo naval vingar retrata, portanto - e infelizmente -, a desterritorialização in situ, uma vez que as populações locais, não estando conectadas com os grandes fluxos globais, arriscam perder o controle sobre "suas

17 Disponível em: <http://www.ofluminense.com.br/noticias $/ 229012$.asp?pstrlink= 2,76,0,229012>. Acesso em: 11 jul. 2009. 
bases territoriais de reprodução e referência" (HAESBAERT, 2004, p. 255) e que o capitalismo globalizado é acompanhado de um processo crescente de exclusão socioespacial. A desterritorialização se expressa igualmente na mudança forçada da poligonal da Resex através da Medida Provisória 462, sem passar pela consulta das populações extrativistas representadas no Conselho Deliberativo, como deveria.

Contudo, as populações pesqueiras procuram resistir a essa lógica externa ao lugar, com a ajuda de redes de horizontalidades. O Movimento da Pesca, citado anteriormente, é, por exemplo, assessorado pelo Conselho Pastoral dos Pescadores. Cita-se também a formação de uma comissão pró-Iguape, formada por várias ONGs ambientalistas e professores de pesquisa da $\mathrm{UFBA}^{18}$. Os pescadores contam igualmente com o apoio do Ministério Público Federal e o do Ministério Público do Estado, que deliberaram, em dezembro de 2008, em audiência pública realizada em Maragojipe, que a ausência de estudos qualificados levará a medidas judiciais contra a implantação do polo em São Roque do Paraguaçu. Trata-se, contudo, de uma relação de forças difícil para os pescadores, uma vez que os interesses do setor privado convergem e recebem o apoio das autoridades políticas em nome do "desenvolvimento". O apoio do Ministério Público pode ser um trunfo para as populações extrativistas locais, porém, não constitui uma garantia, como comprova os esforços semelhantes do MPF do Pará contra o projeto de central hidrelétrica de Belo Monte durante anos, mas que não impediu o leilão realizado no dia 20 de abril de 2010 para a seleção das empresas responsáveis pela obra tão polêmica dos pontos de vista social e ambiental.

\section{CONSIDERAÇÕES FINAIS}

O pretendido desenvolvimento sustentável é, mais uma vez, utilizado como argumento para omitir numerosos impactos sociais, econômicos, culturais e ambientais negativos para as populações tradicionais que o empreendimento do polo naval deve acarretar. Essas populações devem, assim, sofrer uma desterritorialização sensível, pela perda de poder efetivo sobre seu território, reconhecido, no entanto, por lei federal através da criação da Resex no ano de 2000. O principal problema dos pescadores é de habitar uma área considerada estratégica por sua localização geográfica e condições naturais, assim como por já abarcar um

18 A Prof ${ }^{a}$ Guiomar Germani e a autora, ambas professoras do Mestrado em Geografia da UFBA. canteiro naval, facilitando assim o aumento de seu valor para os setores modernos, através de mais investimentos em infraestrutura. Mas, o lugar não é apenas o local onde o Mundo, com sua lógica global, se manifesta; ele é também o espaço banal, onde se formam as resistências a essa mesma lógica. Essa resistência se revela extremamente importante. De fato, ela não se refere apenas à defesa dos grupos tradicionais em escala local. Ela é essencial para um combate, em escala nacional, caso o projeto do polo naval vingue, da mesma forma que foi a luta dos indígenas da Terra Raposa Serra do Sol para a política indigenista brasileira. Com efeito, se o polo for implantado, significará que as unidades de conservação não têm mais garantido o direito à proteção ambiental (no caso das UCs de uso sustentável, frisa-se a proteção socioambiental) na totalidade de seus respectivos territórios. Essa garantia constitui um amparo legal essencial - embora não suficiente - para a sustentabilidade da territorialização das populações nelas inseridas. Aprovar o projeto do polo implicaria abrir uma brecha perigosa para o questionamento dos territórios das áreas protegidas. Resistir aparece, portanto, como imprescindível para garantir os direitos adquiridos e conquistados por populações historicamente excluídas, para garantir a justiça ambiental das populações tradicionais que tanto contribuem para uma real sustentabilidade social, cultural e ambiental.

A autora agradece ao $\mathrm{CNPq}$ pelo apoio à pesquisa.

\section{REFERÊNCIAS}

ALMEIDA, A. W. B. Terras tradicionalmente ocupadas - Processos de territorialização e movimentos sociais. Revista Brasileira de Estudos Urbanos e Regionais, v. 6, n. 1, p. 9-15. maio. 2004.

BAHIA. EIA-RIMA do estaleiro do Paraguaçu, Bahia. Salvador: SUDIC, 2009.

HAESBAERT, R. O mito da desterritorialização. Do "fim dos territórios” à multiterritorialidade. Rio de Janeiro: Bertrand Brasil, 2004.

HARVEY, D. A produção capitalista do espaço. São Paulo: Annablume, 2005.

MARTINEZ ALIER, J. O ecologismo dos pobres. São Paulo: Contexto, 2007.

MESSIAC, A. L'évolution de la géographie des océans et des littoraux face aux perspectives du développement durable au $\mathrm{XXI}^{\circ}$ siècle. Quelles hypothèses envisager? Annales de Géographie, Paris, n. 621, sept.-oct. 2001. 
MONTEIRO, S.S.; PROST, C. Impactos de atividades econômicas sobre os recursos hídricos na Baía do Iguape e Saubara. Relatório PIBIC. Salvador: UFBA, 2009.

MORAES, A. C. R. Contribuições para a gestão da zona costeira do Brasil. Elementos para uma geografia do litoral brasileiro. São Paulo: Annablume, 2007. POLO NAVAL. Uma proposta que não pertence a todos nós. Salvador, 2009. Inédito.

PROST, C. Efeitos da barragem Pedra do Cavalo sobre a pesca artesanal na baía do Iguape. In: ENCONTRO BRASILEIRO DE CIÊNCIAS SOCIAIS SOBRE BARRAGENS, 2., 2007, Salvador. Anais ... . Salvador: UFBA, 2007. CDRom. SANTOS, M. A natureza do espaço. São Paulo: Hucitec, 2002. SANTOS, M. Da totalidade ao lugar. São Paulo: EDUSP, 2008. 